\title{
Bridging Education and Engineering Students through a Wind Energy-Focused Community Engagement Project
}

\author{
Maija A. Benitz ${ }^{1, *(\mathbb{C} \text { and Li-Ling Yang }}{ }^{2}$ \\ 1 School of Engineering, Computing, and Construction Management, Roger Williams University, \\ Bristol, RI 02809, USA \\ 2 Department of Education, Roger Williams University, Bristol, RI 02809, USA; lyang@rwu.edu \\ * Correspondence: mbenitz@rwu.edu
}

Citation: Benitz, M.A.; Yang, L.-L. Bridging Education and Engineering Students through a Wind

Energy-Focused Community Engagement Project. Sustainability 2021, 13, 9334. http://doi.org/ $10.3390 /$ su13169334

Academic Editors: Jan E. DeWaters, Angela R. Bielefeldt and Firoz Alam

Received: 6 July 2021

Accepted: 17 August 2021

Published: 19 August 2021

Publisher's Note: MDPI stays neutral with regard to jurisdictional claims in published maps and institutional affiliations.

Copyright: (c) 2021 by the authors. Licensee MDPI, Basel, Switzerland. This article is an open access article distributed under the terms and conditions of the Creative Commons Attribution (CC BY) license (https:// creativecommons.org/licenses/by/ $4.0 /)$.

\begin{abstract}
Regional growth in offshore wind energy development, changes to the state's K-12 science standards, and a desire to deepen undergraduate student learning coalesced to inspire an interdisciplinary community engagement project bridging university courses in engineering and education. The project consists of three main activities: a professional development event for local fourth grade teachers, five classroom lessons designed and taught by undergraduate engineering and education majors, and a final celebration event, all focused around the topics of wind energy and engineering design. This spring, the project was carried out for the third consecutive year, though each year's implementation has been unique due to the timing of the onset of COVID-19. Analysis of responses from the Teaching Engineering Self-Efficacy Scale and an end-of-semester course survey demonstrate growth in student learning and transferrable skills from participating in the semester-long project. Additionally, exploration of students' narrative work provides a richness to further understanding their growth and challenges they confronted. This interdisciplinary community engagement project will continue into future years, with improvements informed by the findings of this work, most notably with the hope of returning to a fully in-person delivery of lessons to fourth-graders.
\end{abstract}

Keywords: engineering education; energy education; renewable energy; wind energy; community engagement

\section{Introduction}

The third year of our cross-disciplinary community engagement project, bridging college classes in engineering and education, was carried out in the Spring 2021 semester. Despite the continuity of this project from previous years, each implementation has been markedly different from all others, as the COVID pandemic disrupted the project midway through its second year and then dramatically influenced the implementation of its delivery this past spring. Although the pandemic presented ample challenges, it also provided an opportunity for creativity and flexibility, as well a chance to assess the impacts and effectiveness of the various modalities of implementation.

The project, as originally conceived, is comprised of three main activities: a day-long professional development event for the teachers of fourth-grade students (ages 9-10 years) in our local district, an arc of five classroom lessons on wind energy and engineering design, and finally, a celebration event to acknowledge the accomplishments of all project participants. The pilot year of the project, in spring 2019, was implemented as it was originally envisioned.

In year two, the project began as expected but was disrupted midway through by the COVID pandemic. In February 2020, fourth and fifth grade teachers participated in a professional development event on our college's campus. Next, the engineering and education students collaborated on cross-disciplinary teaching teams to design and deliver two lessons in the fourth-grade classrooms before Spring Break. 
Unfortunately, during the university's break it was determined that students would not be returning to campus due to COVID. Within days of the announcement, the project pivoted to cancel all remaining classroom lessons. In an effort to salvage as many learning outcomes as possible, the college students were instructed to complete the planning of the remaining three classroom lessons but would not actually teach those classes. Analysis of students' teaching reflections demonstrated that teaching the lessons was critical to strengthening skillsets, in particular the socioemotional factors, and that just planning the lesson was not sufficient for deeply impacting their learning [1].

This year's project was different, yet again, as we began with the foresight of the impacts of COVID. Before the project launched, it was clear that safety measures, such as social distancing, would need to be upheld. The professional development event for fourth grade teachers was held via Zoom (San Jose, CA, USA) in mid-March, as opposed to the usual in-person workshop. The online format presented minimal challenges, though it might not be as effective at engaging teachers in the small-group engineering activities as compared to an in-person workshop. It was clear from year two that the college students needed to actually teach all five lesson and not just create lesson plans, in order to deepen their content knowledge and develop new skills. For safety purposes, in conjunction with the guidance from our university, it was decided that all five lessons would be taught remotely through Google Classroom (Mountain View, CA, USA). Finally, it was not possible to host nearly 250 fourth graders and their teachers on our campus for a day-long celebration event, so instead, a virtual gathering would occur.

In this work, we explore the learning outcomes for the engineering and education students who participated in the Spring 2021 project, with particular emphasis on the changed nature of the project due to the impacts of COVID. More specifically, we seek to answer the following questions: What impacts has the interdisciplinary community engagement project had on student learning and skill growth? How have the unique implementations of the project across three years affected student growth, most notably with respect to the changes in response to the onset of COVID in the US? Finally, how can this project or other similar projects be improved for the future? The impacts of the project on college student learning are assessed through pre- and post-project non-graded tests, as well as by exploration of students' weekly written reflections and an end-ofsemester course survey. Further, students' written work is examined to identify areas for project improvement.

\section{Background and Motivation}

This community engagement project, often referred to as the KidWind project-named after the wind turbine equipment supplies [2] —was motivated by a combination of factors, including contributing to the world's sustainable future, local growth in wind energy development, changes to the local Kindergarten through 12th grade (K-12) science standards, and the proven effectiveness of community engagement as a pedagogical tool. (In the United States, 12th grade is the final year of secondary school.)

\subsection{Achieving the World's Sustainability Goals}

The United Nations General Assembly published "The 2030 Agenda for Sustainable Development" in 2015, which outlines the steps required for the world to achieve a sustainable future [3]. This report was followed by the development of the 17 Sustainable Development Goals (SDGs) which provide specific targets against which progress can be assessed [4]. "Affordable and clean energy" is addressed by SDG07, which aims to "ensure access to affordable, reliable, sustainable and modern energy for all." SDG12 pertains to "responsible consumption and production," highlighting "the need to improve energy efficiency, increase the share of clean and renewable energies and improve sustainable consumption patterns worldwide" [5]. The importance of renewable energies in achieving our future sustainability goals is highlighted by the fact that two of the UN's 17 SDGs focus on renewable and clean energy sources. This significance is further argued in the 
introduction to the special issue of Sustainability, "Sustainable Conversion of Renewable Energy Sources," by Sher et al., who argue that "sustainable energy is the centre of attention in climactic change agenda" [6].

As the world continues to strive towards a more sustainable future, institutions of higher education must find ways to contribute to the global endeavor. This work recognizes the opportunity for universities to "play a vital role in processes of societal transition that are reliant on educating new generations of citizens and leaders," such as the movement to a more sustainable future, as described by Stephens et al. [7]. The authors describe four activities from transition management, including the operational category, which encompasses "experimentation, project building and implementation, with a focus on learning and co-production of knowledge" [7]. The operational approach, with attention to "experimentation with new and emerging technologies" [7] is adopted in this work, which seeks to encourage dialog and co-learning between university-level students and the local population.

Hoople et al., argue that training the next generation of engineers for a sustainable future requires more than just technical content, but also attention to the social elements [8]. That is, students need to develop a strong understanding of "complex cultures, ways of knowing, and ecosystems in which engineered systems exist" [8]. Moreover, there is a need to ensure that engineering graduates establish, grow, and sustain a variety of transferrable and "soft" skills, such as interdisciplinary communication and collaboration. The social aspects of renewable energy, alongside softer skill development, can be integrated in university coursework through a community engagement framework, which is discussed further below. Through teaching university students and the local community about renewable energy, we ultimately aim to contribute to the achievement of a more sustainable world.

\subsection{Wind Energy Growth in Our Region}

The continued growth of installed wind energy plants in the United States necessitates expanded training and education to provide a skilled workforce [9]. In general, wind energy programs are better developed in Europe, where consortiums of universities offer graduate degrees and perform collaborative research. More specifically, coursework has been motivated by local changes in energy portfolios, for example in Spain, which saw the most growth in installed wind farms in 2019 [10].

The first offshore wind farm in the US was installed in Rhode Island and started producing power in 2016 [11]. Since then, two additional offshore turbines have been installed off the coast of Virginia [12], with many more projects on the horizon. The Biden Administration's climate plan aims for a carbon neutral electricity sector by 2035, which is further driving the growth and expansion of offshore wind farms, especially on the eastern seaboard [13].

The expansion of the wind industry is slated to drive new job growth, which also means we need the workforce to fill those positions. While our project exists at an institution that does not grant advanced degrees in engineering, we nonetheless aim to train a wide range of populations to help meet this demand. For example, the engineering students will not only gain the technical skills for designing and analyzing wind turbines through regular coursework but will expand and deepen their ability to communicate about wind energy to various stakeholders through the community engagement project. These communication skills will serve them well in their role as practicing engineers who must interact with clients and the wider community.

Additionally, while many of the education majors will find jobs as K-12 teachers, some may also seek employment in the wind energy sector. Their participation in the community engagement project has the capacity to enhance their technical content knowledge about wind energy, which would make them well suited for work in such areas as public relations and client services, to name a few.

Moreover, as public perceptions about wind energy continue to evolve [14], this project not only provides education to fourth graders, but also to their families with whom the 
fourth graders may share their new knowledge. Finally, as the renewable energy sector continues to expand, the fourth graders could very well land in careers in the wind energy industry in the future.

\subsection{Changes to the Science Standards in K-12}

In 2012 the National Research Council (NRC) published A Framework for K-12 Science Education, which was intended to guide the development of the next-generation set of science standards, Next Generation Science Standards (NGSS) [15], for voluntary adoption by states. This new framework presents a new "vision for education in the sciences and engineering in which students, over multiple years of school, actively engage in scientific and engineering practices and apply crosscutting concepts to deepen their understanding of the core ideas in these fields" [15]. The new vision proposed in the framework and subsequent standards cannot be achieved "unless the other components of the systemcurriculum, instruction, professional development, and assessment-change so that they are aligned with the framework's vision" [16]. Rhode Island was the first state to adopt the NGSS in 2013, and Rhode Island public schools have since been working toward full implementation by aligning their curriculum and instruction to the new standards [17].

\subsection{Community Engagement as an Effective Pedagogy}

Community engagement, under the umbrella of service learning, continues to see increased adoption as a core pedagogy in engineering curriculum for its demonstrated effectiveness in deepening student learning and enhancing skills [18]. Hatcher and Bringle's definition of service-learning states that "student participate in an organized service activity that meets identified community needs," and that reflections by students lead to "further understanding of course content, broader appreciation of the discipline, and an enhanced sense of civic responsibility" [19]. The importance of students' reflection on their experiences is embraced in this work and used as method to assess learning outcomes [20].

Community engagement projects are being implemented in many different areas of engineering education. In engineering courses, these projects are most commonly integrated in first year [21] and capstone courses [22,23]. Outside of coursework, student organizations such as Engineers Without Borders [24] and the engineering professional societies, are performing community engagement activities as well [25]. Other examples include work in churches [26] and at STEM summer camps [27].

In this work, community engagement is implemented not only to enhance the education of the engineering students while addressing a community need, but also a means to bridge diverse disciplines across the university - in this case, engineering and education. Service learning and community engagement projects have connected various disciplines with engineering. For example, art and engineering students collaborated to create touch boards for young people on the autism spectrum [28]. Another project linked architecture and engineering students to redesign a field house for the local city [29]. Service-learning projects have also integrated more than just two disciplines, for example students from industrial distribution, technology management, and sociology students worked to address food disparity issues in their local region [30].

\section{Project Implementation}

The semester-long community engagement project bridges courses in engineering and education to create cross-disciplinary teams of students who work collaboratively to develop and implement five classroom lessons for fourth grade students in the local school district.

\subsection{Course Descriptions}

The engineering course, ENGR340: Sustainable Energy Systems, is an upper-level elective for Engineering Majors specializing in mechanical, electrical, or environmental engineering. It is regularly enrolled with a mix of juniors and seniors (final two years 
of university study). The course focuses primarily on wind energy, both for its regional relevance and the instructor's area of expertise. Solar and marine renewables are also explored. The students complete an arc of engineering assignments beginning with wind resource assessment from the National Oceanic and Atmospheric Administration (NOAA) weather buoys, through designing industry-scale wind turbine blades and assessing their performance with blade element momentum (BEM) theory. The course uses the textbook Wind Energy Explained by Manwell et al. [31]. Mini-reports of their engineering analysis provide opportunities for growth in written communication, while the KidWind project complements that aim with a focus on verbal communication-both to the fourth graders, and with their education counterparts and fourth grade host teachers.

EDU342: Teaching Inquiry Science in the Elementary School, is the second course in the two-semester sequence of elementary science methods courses, which are required for elementary education majors. Most students enrolled in this course are sophomores. The elementary science methods courses integrate four different approaches, described here. First, Science/Engineering Content includes coverage of the core ideas in physical science, earth and space science, life science, and engineering, technology, and application of science that a prospective teacher might encounter at the elementary level. The NGSS guide the content selection. Next, Applications of Inquiry and Engineering Design provides students with experience in science inquiry and engineering design through practices similar to those used by scientists/engineers. The third approach, Science/Engineering Activities for Children, gives future teachers, acting in the role of students, an introduction to an extensive array of learning activities. Building confidence and interest in science inquiry/engineering design, and heightening awareness of ways to learn them, are the principal goals of this approach. Finally, the Reflective approach engages future teachers in a variety of learning experiences coupled with ongoing reflection to provide powerful insights about science/engineering teaching and learning.

\subsection{The KidWind Project: Bridge between University and Local Community}

\subsubsection{Professional Development Event}

The project begins each year with a day-long professional development event for all fourth-grade teachers in the local school district. The purpose of the workshop is twofold: first, to bring the teachers up to speed with the teaching, learning, and assessment of engineering core ideas and practices as envisioned in the framework and the NGSS; secondly, to address and surmount elementary school teachers' common fear or lack of confidence in teaching science and engineering. In past years, this event was held on our university's campus, including a catered lunch for all participants, which provided an opportunity to get to know one another outside of the workshop activities. This year, the workshop was held over Zoom (San Jose, CA, USA), as COVID prevented us from convening face-to-face.

This year's professional development workshop was held one week ahead of our students' first delivered lessons in the schools. Thirteen fourth grade teachers, plus a special educator, attended the event this year. About half of the teachers were new to the project, having either just joined the district or having taught a different grade the previous year. Because of the mix of experiences with the project from previous years, the workshop began with a basic overview of the work. A pre-assessment was administered to all workshop participants, gauging their confidence and self-efficacy in teaching engineering content.

The workshop provided the welcome opportunity to discuss how to best facilitate the lessons during this challenging year, as our college students would be teaching their fourth graders through Google Classroom (Mountain View, CA, USA) instead of face-to-face. Nine of the thirteen fourth grade classrooms met for in-person classes, while the other four were doing distance learning. Regardless of the modality of the fourth graders' learning, out of an abundance of caution, guided by our university's COVID policy, the college students would not engage with the fourth graders face-to-face. As such, all lessons would 
need to be delivered remotely through Google Classroom (Mountain View, CA, USA), the district's chosen teaching platform.

During the workshop, each teacher was given $15 \mathrm{~min}$ to create two slides-one to describe their fourth graders and another to share best practices for teaching their students online. These slides were then shared with the group, with an opportunity for discussion amongst the teachers. After the workshop, the slides were provided to the engineering and education students, as they began the process of designing their first lessons.

The latter half of the workshop focused on the engineering design process and the NGSS. The teachers were first asked to share their thoughts about what engineering is and why teaching engineering in K-12 is important. They were then introduced to the engineering practices and core ideas that are explicitly included in the NGSS, which Rhode Island adopted in 2013. The guidelines of the Egg Drop project, a common engineering design classroom activity, were shared with the teachers as an example to illustrate the common steps included in the engineering design process. Lastly, the teachers engaged in a spool racer design activity using the introduced engineering design process, followed by an activity debrief that was guided by the three prompts below:

- How did the engineering design process help improve your spool racer designs by meeting the design criteria and constraints?

- What engineering practices and core ideas did you use in the design process?

- The targeted NGSS performance expectation for the spool racer design activity is "Generate and compare multiple possible solutions to a problem based on how well each is likely to meet the criteria and constraints of the problem" for Grades 3-5 (National Science Teaching Association, 2014). After experience the spool racer design activity as a leaner, what ideas do you have to help your fourth-grade students meet the NGSS performance expectations relating to engineering design?

\subsubsection{Five Classroom Lessons}

The community engagement project reaches all four elementary schools in the local school district, with thirteen total fourth grade classrooms. Five lessons are designed and delivered in each of the fourth-grade classrooms by the same cross-disciplinary team of engineering and education students, such that the fourth graders get to know their college teachers as the project progresses. Each elementary school principal identified a weekly date and time for the five lessons to be delivered over the course of six weeks (including an off week for Spring Break). The college students signed up for their teams based on their calendar availabilities and the criteria that each team should include two engineering students and two education students.

Each team of engineering and education students are then split into two pairs of crossdisciplinary partnerships to develop the lesson plans. Pair one designs lessons one and three, while pair two focuses on lessons two and four. Finally, the entire team collaborates to develop the fifth lesson. Each team meets with either the engineering or education faculty member for a lesson review meeting the week prior to teaching. Upon approval of the finalized lesson plan, it is emailed to the host fourth grade teacher, including any slides, worksheets, and other supplemental material.

Each teaching team creates lesson plans following the same framework of topics. Lesson 1 focuses on energy and energy transfers, to prepare the fourth graders to think about these concepts as they relate to wind turbines. Next, Lesson 2 introduces wind-how it is generated and a discussion of its resource. Screenshots from one teaching team's lesson are provided in Figure 1, where they used an egg and bottle to demonstrate pressure gradients. The engineering design process is the main focus of Lesson 3, with a brief introduction of wind turbines and their components. In Lessons 4 and 5 the fourth graders spend time designing, building, and testing windmills and wind turbines, guided by the engineering design process. Mechanical energy is the focus of Lesson 4, where students measure the weight lifted by their windmills. In Lesson 5, students begin to explore 
electrical energy using multimeters and/or LEDs. Fourth graders participating in hands-on learning activities are shown in Figure 2.

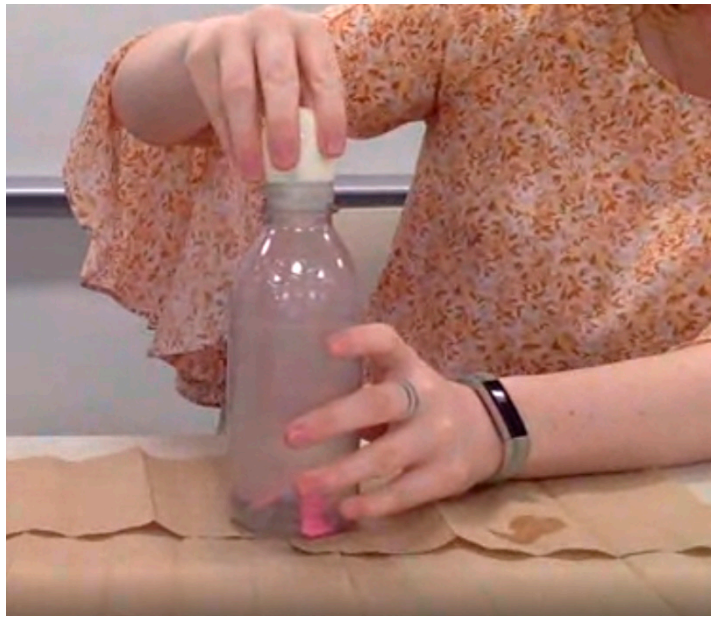

(A)

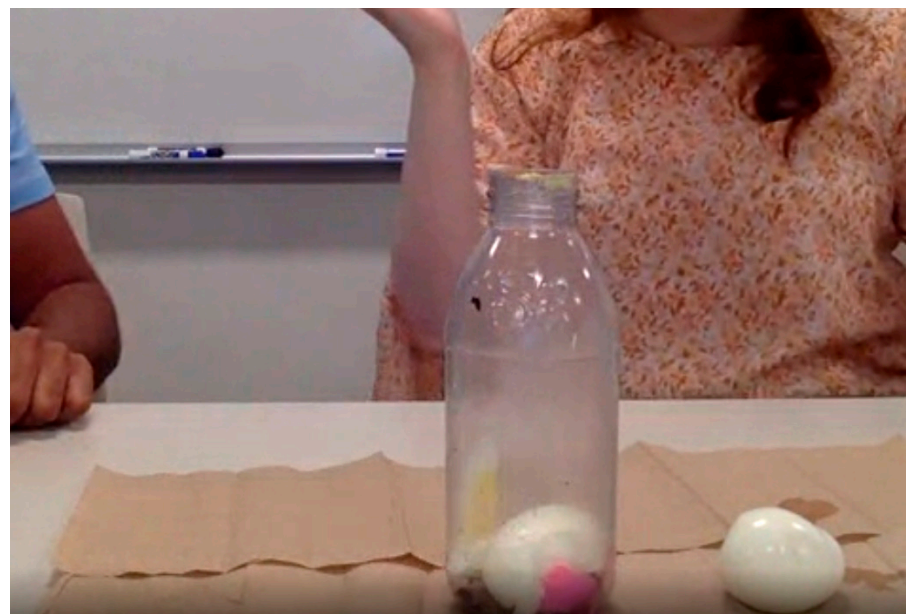

(B)

Figure 1. As part of their lesson on how wind is generated, a teaching team places an egg atop a bottle that contains a lit match (A) The egg is pushed inside the bottle due to the differential air pressure (B). Images captured from Google Classroom (Mountain View, CA, USA).

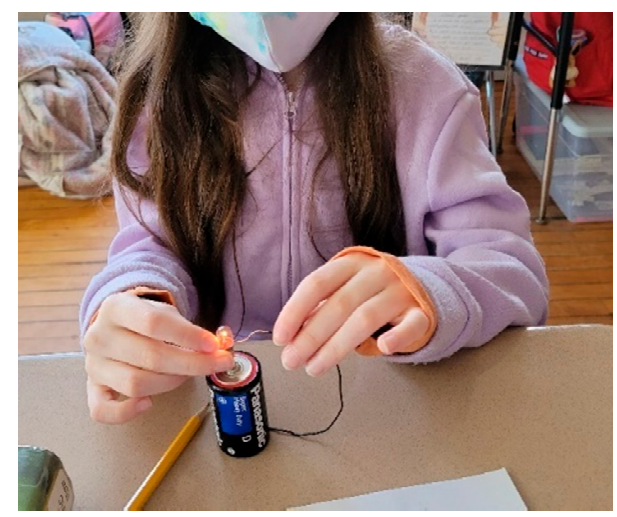

(A)

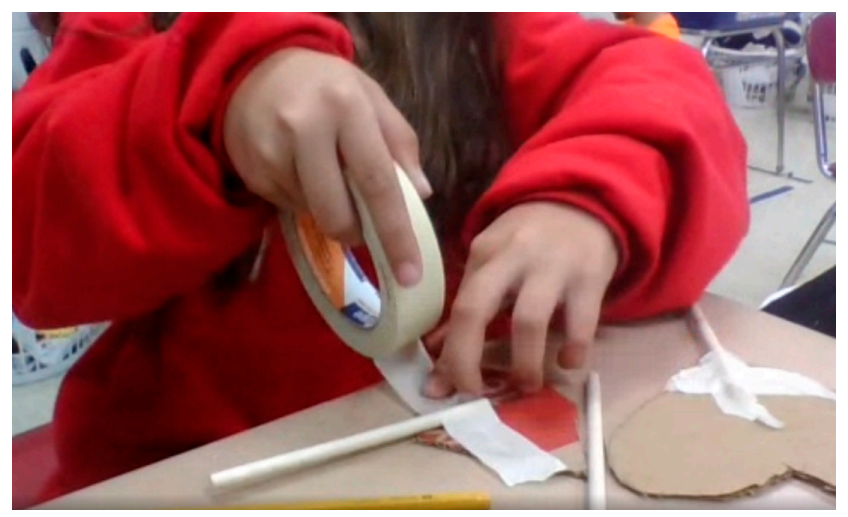

(B)

Figure 2. A fourth grade in-person learner completes a hands-on activity about energy and energy transfers using a battery and a light bulb (A) and another in-person learner constructs blades for the Vernier model wind turbine (B).

This year, the KidWind turbine kits (Vernier Software and Technology, Beaverton, OR, USA) were delivered to all fourth-grade classrooms with in-person learners [2]. Each fourth grader received enough wooden dowels to create their own sets of blades. Each classroom was supplied with 4-5 wind turbines, such that the fourth graders took turns attaching their blades to the hub and performing their measurements, to maintain social distancing throughout their work. This undoubtedly presented a challenge to the project, which, in previous years, had involved ample teamwork. The college students assigned to those classrooms were also given KidWind turbines (shown in Figure 3), such that they could guide and demonstrate their use on screen via Google Classroom (Mountain View, CA, USA). 


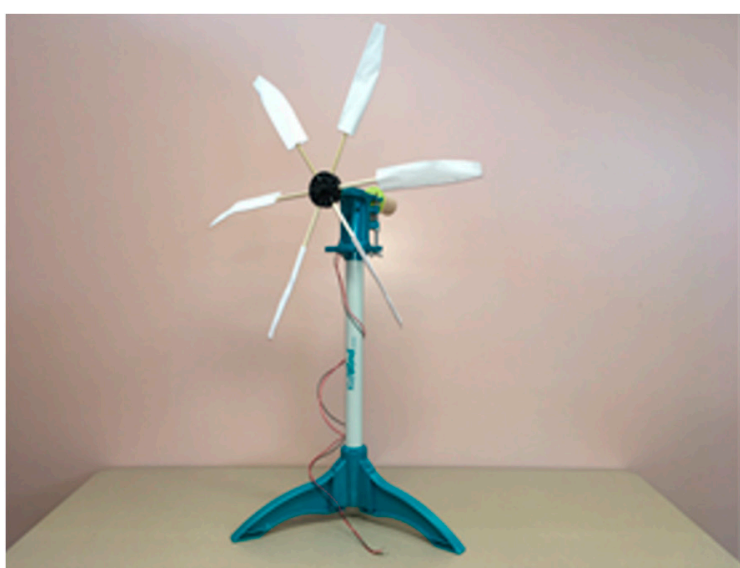

(A)

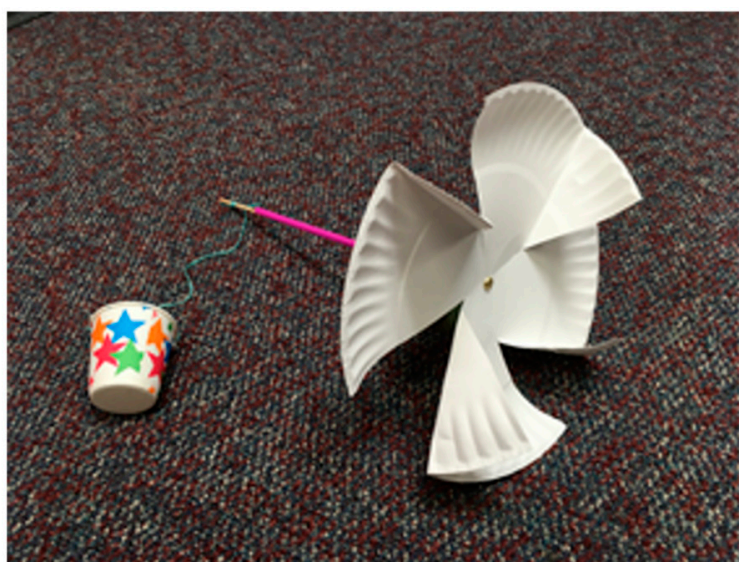

(B)

Figure 3. Four to Five KidWind Basic Wind Experiment Kits from Vernier (Beaverton, OR, USA) were provided to each in-person learning classroom (A) [2], while DIY windmill kits were given to all distance-learners (B) [32].

Unfortunately, we did not have enough KidWind kits to provide to each of the 74 fourth graders doing distance-learning at home. Instead, kits were assembled for each student to create their own mini windmill (schematically shown in Figure 3) using skewers, foam cylinders, paper plates, straws, cups, and tape [32]. These kits were assembled and delivered to the front office of each of the students' home elementary school, for a parent or guardian to pick up and bring home. These kits were also provided to each of the college students teaching distance learners, so that they could also guide the assembly and use over the computer screen.

More so than in previous years, the lessons were anchored by slides as the lessons were delivered entirely remotely. Most of the in-person learning classrooms used individual Chromebooks such that each fourth-grade student could interact with the lesson by video, audio, and by typing. All of the distance learners interacted in those ways as well. Despite the heavy use of slides, the lessons were very interactive. The slide show format allowed the college students to post links, share short videos, and display input from the fourth graders. Kahoot [33] was frequently used as a platform for participation, where the fourth graders could vote in a quiz-like format and then have their pooled responses displayed on the screen. Another popular tool was Jamboard (Google, Mountain View, CA, USA) [34], which teaching teams effectively leveraged for soliciting ideas and input from the fourth graders. The chat tool in Google Classroom (Mountain View, CA, USA) was another avenue for encouraging participation. Many teaching teams developed digital worksheets, and a few decided to create paper worksheets which they delivered to the front offices of the school in advance of their lesson. Finally, assessments were performed upon completion of most lessons, and many teams elected to use Google Forms (Mountain View, CA, USA) for collecting that data.

\subsubsection{Celebration Events}

Upon completion of the five classroom lessons, the project culminates with a celebration event. This was originally proposed as a competition event for the fourth graders to test the power and energy performance of their designed and built wind turbines, but it was later recast as a celebration event upon the advice of the fourth-grade teachers.

The pilot year of the project included a celebration event on our university's campus, in which nearly 250 fourth grade students arrived on school buses and spent the day participating in a round robin of activities spread throughout our gym/fieldhouse. Engineering design activities, as well as a station with a wind tunnel to test the wind turbines' performance, were facilitated by the engineering and education majors. Further, we invited 
local practicing engineers to meet with each team of fourth graders to review their wind turbine designs.

In the second year of the project, we anticipated repeating the success of the first celebration event. However, the closure of our college campus midway through the project led to the event being cancelled outright.

This year, with gained experience in participating and facilitating online events, the celebration event was reintroduced but at a smaller scale than the pilot year. Individualized celebration events were hosted on Zoom (San Jose, CA, USA) or Google Meet (Mountain View, CA, USA), facilitated by a student-teacher from each of the fourth-grade classrooms. Each fourth-grade participant was given a certificate to acknowledge their completion of the KidWind 2021 project. Additionally, customized party hats, with a photo of the Block Island wind farm and the phrase "I am a wind energy engineer" were given to each fourth grader, fourth grade teacher, engineering student, and education student. The celebration materials are shown in Figure 4. A Kahoot game was created by the project's research assistants with a focus on the learning achievements of the fourth graders. Finally, the celebration events provided an opportunity for the fourth graders and their student-teachers to say goodbye to one another.

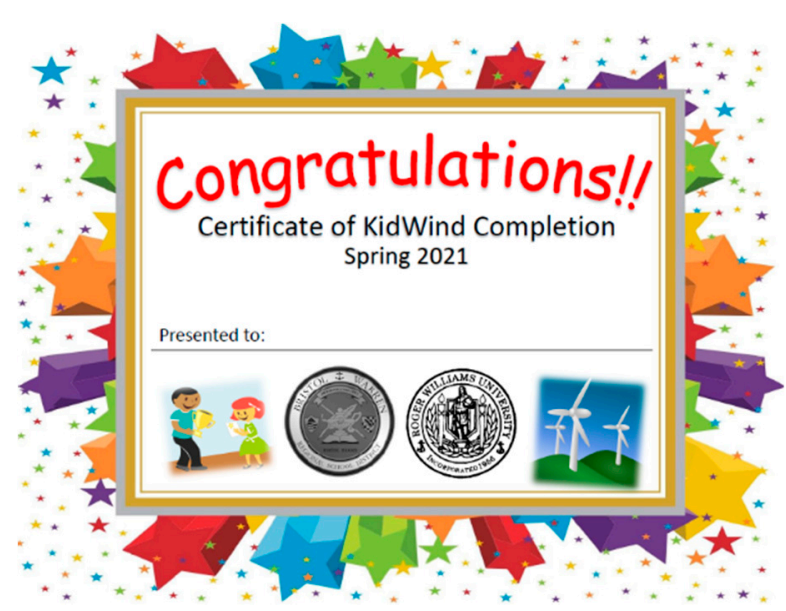

(A)

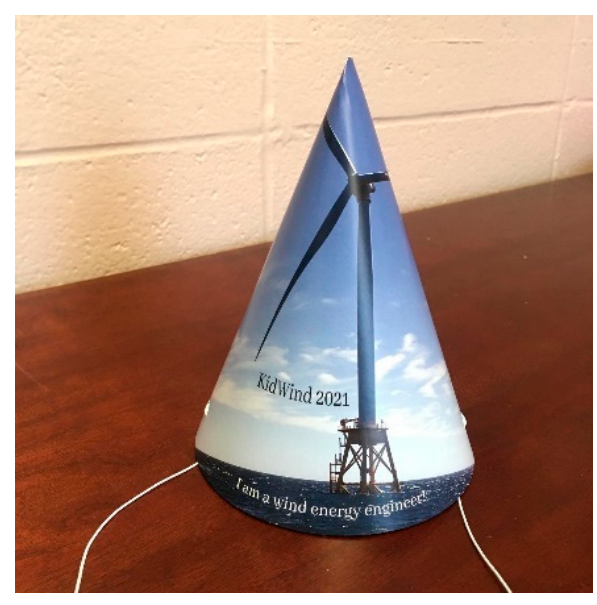

(B)

Figure 4. Certificates of completion (A) and customized party hats (B) were provided to each project participant.

\section{Methods}

To gather the necessary data for answering our research questions, pre- and postproject assessments are administered to each participant population — fourth graders and their teachers, as well as the education and engineering college students. All participants are eligible for study participation, but it is not a requirement for participating in the other project components. That is, individuals may teach or join classroom lessons but not complete the pre- or post-assessments. Participation is not incentivized. Each population completes an informed consent process, which is approved by our institution's Human Subject Review Board. The pre-tests and post-tests are administered to all willing participants prior to the first project activity and following the final project component, respectively.

The fourth-grade teachers complete pre-tests at the beginning of the professional development event. In the first two years of the project, a paper pre-test was used. More recently, the pre-test has been moved to Google Forms (Mountain View, CA, USA), such that it can be administered remotely, and data can be collected more easily. The online platform also allows the teachers more privacy while completing the assessment. The same assessment is administered as a post-test following the end-of-project celebration event. The teachers are reminded that their performance on the assessment does not serve as a 
judgment of their teaching. Further, the teachers are informed that all responses will be fully anonymized before analysis. Responses from the pre- and post-tests are compared to assess changes in the teachers' confidence in teaching engineering concepts and supporting their students in engineering explorations.

The fourth-graders complete pre-tests on paper in their classrooms with only their own teachers present. The college students, nor the university faculty, are present for the test administration. The students are told that they will not be graded on their performance and should be as honest as possible when completing the assessment. The pre-test contains questions about the steps of the engineering design process, concepts in energy, and basic concepts relating to wind turbines. The same assessment is administered to the fourthgrade students following the celebration event. Again, the assessment is administered in paper form in their home classrooms, without the presence of the college students nor faculty. The responses from before and after participation in the KidWind Project are compared to assess changes in the fourth graders' understanding of the engineering design cycle, as well as concepts of energy and wind turbines.

Finally, pre- and post-project assessments were administered to all university students enrolled in the engineering and education courses. The pre-project assessments were administered in mid-March prior to the first weeks of classroom lessons. After students had completed teaching the fifth and final lesson, the post-project assessment was given. The same assessment is administered at the start and end of the project to facilitate simple comparison of assessment responses. Students are reminded at each assessment point that participation in the study is voluntary. Further, they are reminded that their choice to participate has no impact on their course grade, nor does their performance on the assessment. The students complete the assessments in the absence of the instructors.

The Teaching Engineering Self-Efficacy Scale (TESS), originally designed to assess the engineering teaching self-efficacy of K-12 teachers, was adapted for use [35,36]. The scale included 41 questions, spanning six subscales. The TESS was edited for different participant populations in our study (education and engineering undergraduates, and fourth-grade teachers) as well as for length with the intention of the assessment taking no longer than $20 \mathrm{~min}$. The included categories include Engineering Pedagogical Content Knowledge Self-Efficacy, Motivational Self-Efficacy, and Outcomes Expectancy, where the authors of the scale adopt Bandura's model of self-efficacy [36].

The TESS uses a Likert-type scale to measure the degree to which survey participants agree with a list of statements. The authors of this work adopt the approach presented by Sullivan and Artino [37] when analyzing and presenting results gathered with Likert scales. Sullivan and Artino state that "means are often of limited value [ ... ]. Furthermore, because the numbers derived from Likert scales represent ordinal responses, presentation of a mean to the 100th decimal place is usually not helpful or enlightening to readers" [37]. As such, we have chosen to analyze the TESS data using median scores and their differences and have purposely omitted metrics such as means and standard deviations.

In addition to the post-test, a survey was administered to the engineering students upon completion of the semester. The survey asks students to identify skills they gained from participation in the semester-long project, as well as to self-assess whether or not the project was valuable to their learning. Finally, teacher research is performed on the college students' artifacts from the course [38-40]. That is, narratives from the engineering students' weekly reflections and project portfolios are examined for an added assessment of their skill growth and feedback about the project.

The project assessment outcomes reported in this work relied on self-reported data, which can contain response bias. In their work on measuring bias in self-reported data, Rosenman et al. states: "There are many reasons individuals might offer biased estimates of self-assessed behaviour, ranging from a misunderstanding of what a proper measurement is to social-desirability bias, where the respondent wants to 'look good' in the survey, even if the survey is anonymous" [41]. To reduce the impact of response bias, project assessment was performed in a variety of ways and over a span of three years. 


\section{Assessment and Discussion}

Assessment of learning outcomes, skills growth, and overall project success is performed here. While all project participants, including college students, fourth graders, and the fourth-grade teachers, complete pre- and post-tests, the focus of this paper is on the college students' learning outcomes and skill growth. Assessment of the fourth graders and their teachers will be provided in another work.

\subsection{Pre- and Post-Project Assessments}

Changes between pre- and post-assessment scores are analyzed here to measure changes in students' teaching self-efficacy after completing this interdisciplinary community engagement project.

The Engineering Pedagogical Content Knowledge Self-Efficacy subscale, from TESS [35], included nine prompts, provided in Table 1 alongside engineering and education students median responses from the pre- and post-tests. The changes between median pre- and post-test scores were uniformly positive for both the engineering and education students who completed this year's project, demonstrating growth in their self-efficacy in teaching engineering concepts. All of the post-test median scores across both populations had values of 5 or greater, indicating strong agreement with each of the survey prompts.

Table 1. Engineering and education students' median responses to the Engineering Pedagogical Content Knowledge Self Efficacy prompts from the adapted TESS scale, as well as change in median score for each prompt.

\begin{tabular}{|c|c|c|c|c|c|c|}
\hline \multirow{2}{*}{$\begin{array}{c}\text { Engineering Pedagogical Content Knowledge Self-Efficacy: } \\
\text { Survey Prompts }\end{array}$} & \multicolumn{3}{|c|}{ Engineering Students $(n=16)$} & \multicolumn{3}{|c|}{ Education Students $(n=24)$} \\
\hline & Pretest & Post-Test & Change & Pretest & Post-Test & Change \\
\hline I can explain the different aspects of the engineering design process. & 4 & 6 & +2 & 3 & 6 & +3 \\
\hline I can assess my students' engineering design products. & 4 & 6 & +2 & 3 & 6 & +3 \\
\hline I know how to teach engineering design process effectively. & 3.5 & 6 & +2.5 & 3 & 6 & +3 \\
\hline I can teach engineering as well as I do most subjects. & 4 & 5 & +1 & 2 & 5 & +3 \\
\hline I can employ engineering activities in my classroom effectively. & 4 & 6 & +2 & 3 & 5 & +2 \\
\hline I can discuss how engineering is connected to our daily life. & 5 & 6 & +1 & 4 & 6 & +2 \\
\hline $\begin{array}{c}\text { I can create engineering activities at the appropriate level for my } \\
\text { students. }\end{array}$ & 4 & 5 & +1 & 4 & 6 & +2 \\
\hline $\begin{array}{l}\text { I can recognize and appreciate the connections between engineering } \\
\text { and other STEM fields. }\end{array}$ & 5 & 6 & +1 & 5 & 6 & +1 \\
\hline $\begin{array}{l}\text { I can guide my students' solution development with the } \\
\text { engineering design process. }\end{array}$ & 4 & 6 & +2 & 3 & 5 & +2 \\
\hline Subscale Median & 4 & 6 & +2 & 3 & 6 & +3 \\
\hline
\end{tabular}

Likert Scale: 1 = Strongly Disagree, 6 = Strongly Agree.

Four prompts were provided to assess students' motivational self-efficacy before and after completing this project. The prompts and responses are provided in Table 2. Changes over time were nearly uniformly positive showing that students grew in their self-efficacy in motivating the fourth graders in their classroom. Change in median scores for the first prompt indicate that the education students did not feel they had improved in their ability to motivate students with low interest in engineering. The engineering students entered the project with lower motivation self-efficacy than their education partners, but by the end of the project, selected equally high scores.

Table 2. Responses to the Motivational Self-Efficacy survey prompts from engineering and education students, shown with median pre- and post-test scores, as well as the change in median scores for each prompt.

\begin{tabular}{|c|c|c|c|c|c|c|}
\hline \multirow{2}{*}{ Motivational Self-Efficacy: Survey Prompts } & \multicolumn{3}{|c|}{ Engineering Students $(n=16)$} & \multicolumn{3}{|c|}{ Education Students $(n=24)$} \\
\hline & Pretest & Post-Test & Change & Pretest & Post-Test & Change \\
\hline $\begin{array}{c}\text { I can motivate students who show low interest in learning } \\
\text { engineering. }\end{array}$ & 4 & 5 & +1 & 5 & 5 & 0 \\
\hline I can increase students' interest in learning engineering. & 4 & 5 & +1 & 5 & 5.5 & +0.5 \\
\hline
\end{tabular}


Table 2. Cont.

\begin{tabular}{|c|c|c|c|c|c|c|}
\hline \multirow{2}{*}{ Motivational Self-Efficacy: Survey Prompts } & \multicolumn{3}{|c|}{ Engineering Students $(n=16)$} & \multicolumn{3}{|c|}{ Education Students $(n=24)$} \\
\hline & Pretest & Post-Test & Change & Pretest & Post-Test & Change \\
\hline $\begin{array}{l}\text { Through engineering activities, I can make students enjoy the class } \\
\text { more. }\end{array}$ & 4 & 6 & +2 & 5 & 6 & +1 \\
\hline $\begin{array}{l}\text { I can encourage my students to interact with each other when } \\
\text { participating engineering activities. }\end{array}$ & 4 & 6 & +2 & 5 & 6 & +1 \\
\hline Subscale Median & 4 & 5 & +1 & 5 & 5 & +0 \\
\hline
\end{tabular}

1 = Strongly Disagree, 6 = Strongly Agree.

Finally, the Outcomes Expectancy subscale was measured with five prompts, which are provided in Table 3 . The growth in median scores over time was consistently positive in this subscale. The education students demonstrated higher Outcomes Expectancy scores on many of this subscale's items in the pre- and post-test as compared to the engineering students. Nonetheless, engineering students showed an equal or greater degree of improvement on each item compared to the education students.

Table 3. Median scores from engineering and education students' responses to Outcomes Expectancy survey prompts, as well as change in median scores from before and after completing the project.

\begin{tabular}{|c|c|c|c|c|c|c|}
\hline \multirow{2}{*}{ Outcomes Expectancy: Survey Prompts } & \multicolumn{3}{|c|}{ Engineering Students $(n=16)$} & \multicolumn{3}{|c|}{ Education Students $(n=24)$} \\
\hline & Pretest & Post-Test & Change & Pretest & Post-Test & Change \\
\hline $\begin{array}{c}\text { I am generally responsible for my students' achievements in } \\
\text { engineering. }\end{array}$ & 4 & 5 & +1 & 5 & 5 & 0 \\
\hline $\begin{array}{c}\text { When my students do better than usual in engineering, it is often } \\
\text { because I exerted a little extra effort. }\end{array}$ & 4 & 5 & +1 & 4 & 5 & +1 \\
\hline $\begin{array}{l}\text { My effectiveness in engineering teaching can influence the } \\
\text { achievement of students with low motivation. }\end{array}$ & 4.5 & 5.5 & +1 & 5 & 6 & +1 \\
\hline $\begin{array}{c}\text { If I increase my effort in engineering teaching, I see significant } \\
\text { change in students' engineering achievement. }\end{array}$ & 4 & 5 & +1 & 5 & 6 & +1 \\
\hline I am responsible for my students' competence in engineering. & 4 & 5 & +1 & 5 & 5 & 0 \\
\hline Subscale Median & 4 & 5 & +1 & 5 & 5 & +0 \\
\hline
\end{tabular}

$1=$ Strongly Disagree, 6 = Strongly Agree.

The modified TESS pre-test was administered at the start of each year's project. However, due to the complications of COVID midway through the second year, the posttest was not administered. To explore the changes in perceived self-efficacy and outcomes expectancy over time, the results from 2019 and 2021 are compared here, as both the pre- and post-tests were administered in those years. The median scores on the preand post-test subscales from engineering and education students in the pilot year (2019) and the most recent year (2021) are provided in Table 4, alongside the change between medians. In both years, across both populations, none of the median subscale scores decreased from before to after the project was completed. In fact, many of the subscale scores increased, indicating that the project had a positive impact on students' growth. The strongest and most consistent increases are shown in the engineering pedagogical knowledge self-efficacy subscale.

Table 4. Median change in pre- and post-test scores from engineering and education students, in the pilot project in 2019 and the most recent project in 2021.

\begin{tabular}{|c|c|c|c|c|}
\hline \multirow{2}{*}{ Adapted TESS Subscales } & \multicolumn{2}{|c|}{$\begin{array}{c}\text { Engineering Students } \\
\text { Median Pre/Post Score (Change) }\end{array}$} & \multicolumn{2}{|c|}{$\begin{array}{c}\text { Education Students } \\
\text { Median Pre/Post Score (Change) }\end{array}$} \\
\hline & $2019(n=28)$ & $2021(n=16)$ & $2019(n=43)$ & $2021(n=24)$ \\
\hline Engineering pedagogical content knowledge self-efficacy & $5 / 6(+1)$ & $4 / 6(+2)$ & $3 / 5(+2)$ & $3 / 6(+3)$ \\
\hline Motivational self-efficacy & $4 / 5(+1)$ & $4 / 5(+1)$ & $4 / 6(+2)$ & $5 / 5(+0)$ \\
\hline Outcome expectancy & $5 / 5(+0)$ & $4 / 5(+1)$ & $4 / 5(+1)$ & $5 / 5(+0)$ \\
\hline
\end{tabular}




\subsection{End of Semester Project Survey (Engineering)}

At the conclusion of the semester, a survey was administered to the engineering students to assess their learning in the community engagement project. The responses provide insight about the engineering students' self-perceived growth in various skills, as well as a general sense for their perception of the project. This survey has been administered every year since the project was piloted, which allows for comparison of responses across the three years of implementation. In 2019, the pilot year, the project was implemented entirely in person. The second year of the project began as an in-person project, but was pivoted to be remote midway through, due to the arrival of COVID-19 in the US. Finally, this year's project was delivered entirely remotely to accommodate safety precautions necessitated by the ongoing pandemic.

Students were given the prompt "I gained or enhanced the following skills from participating in the KidWind Community Engagement Project (select as many as apply)" followed by a list of sixteen items. The responses from all three years of the project are provided in Table 5. Each year, all of the survey participants selected teamwork as a gained or new skill. Further, communication, thinking on your feet, and project planning have consistently been identified by a majority of students throughout the lifetime of the project, as indicated by the average scores in the righthand column. This year's project had marginally higher response rates to communication and thinking on your feet, which may be a reflection of the added challenges of communicating through online platforms and the flexibility necessitated by the enhanced use of technology.

Table 5. Responses to survey question "I gained or enhanced the following skills from participating in the KidWind Community Engagement Project (select as many as apply)" from the past three years of the project, given as a percentage of students who selected the item.

\begin{tabular}{|c|c|c|c|c|}
\hline Skills Gained or Strengthened & $\begin{array}{c}2021 \\
(n=16)\end{array}$ & $\begin{array}{c}2020 \\
(n=21)\end{array}$ & $\begin{array}{c}2019 \\
(n=23)\end{array}$ & Average \\
\hline Teamwork & $100.0 \%$ & $100.0 \%$ & $100.0 \%$ & $100.0 \%$ \\
\hline Communication & $100.0 \%$ & $95.2 \%$ & $91.3 \%$ & $95.5 \%$ \\
\hline Thinking on your feet & $100.0 \%$ & $95.2 \%$ & $87.0 \%$ & $94.1 \%$ \\
\hline Project planning & $93.8 \%$ & $100.0 \%$ & $87.0 \%$ & $93.6 \%$ \\
\hline Applied what you learned in class in a real-world setting & $68.8 \%$ & $95.2 \%$ & $95.7 \%$ & $86.6 \%$ \\
\hline Cross-disciplinary collaboration & $87.5 \%$ & $76.2 \%$ & $91.3 \%$ & $85.0 \%$ \\
\hline Gain hands-on experience in a community setting & $68.8 \%$ & $100.0 \%$ & $82.6 \%$ & $83.8 \%$ \\
\hline Science communication & $81.3 \%$ & $90.5 \%$ & $78.3 \%$ & $83.3 \%$ \\
\hline Problem solving and critical thinking & $68.8 \%$ & $85.7 \%$ & $73.9 \%$ & $76.1 \%$ \\
\hline Deepened understanding of course material & $75.0 \%$ & $81.0 \%$ & $69.6 \%$ & $75.2 \%$ \\
\hline Flexibility & $75.0 \%$ & $85.7 \%$ & $56.5 \%$ & $72.4 \%$ \\
\hline Listening skills & $62.5 \%$ & $66.7 \%$ & $73.9 \%$ & $67.7 \%$ \\
\hline Understand both assets and needs in communities & $50.0 \%$ & $71.4 \%$ & $56.5 \%$ & $59.3 \%$ \\
\hline $\begin{array}{c}\text { Meeting others who enjoy serving the community and } \\
\text { building personal networks }\end{array}$ & $37.5 \%$ & $66.7 \%$ & $69.6 \%$ & $57.9 \%$ \\
\hline $\begin{array}{l}\text { Build professional connections useful for future } \\
\text { internships or jobs }\end{array}$ & $43.8 \%$ & $57.1 \%$ & $43.5 \%$ & $48.1 \%$ \\
\hline $\begin{array}{c}\text { Learning more about cultures/populations different } \\
\text { from your own }\end{array}$ & $31.3 \%$ & $52.4 \%$ & $52.2 \%$ & $45.3 \%$ \\
\hline Average & $71.5 \%$ & $82.4 \%$ & $75.6 \%$ & \\
\hline
\end{tabular}

Perhaps unsurprisingly, the prompts with terms such as "real world setting" and "community setting" were selected by fewer students this year than in previous years when at least part of the project was administered face-to-face. Further, fewer of this year's participants selected "meeting others who enjoy serving the community and building personal networks," likely due to the fact that most engineering students never met their education partners face-to-face, and even more certainly did not meet their fourth graders or fourth grade teacher. 
Despite the lower response rates to many items from this year's project participants, the data still show that the project was valuable for growing students' skills across a variety of areas. In general, the trends in response rates match fairly closely across the years, with many of the same skills rising to the top, while other items consistently falling towards the bottom.

The end of semester project survey also asked students to respond to two questions on a Likert-type scale where $1=$ strongly disagree and $5=$ strongly agree. The first prompt stated, "Whether I liked it or not, the KidWind project was valuable for my learning" and the second said, "I enjoyed the KidWind project". The responses across all three years of the project are provided in Figures 5 and 6.

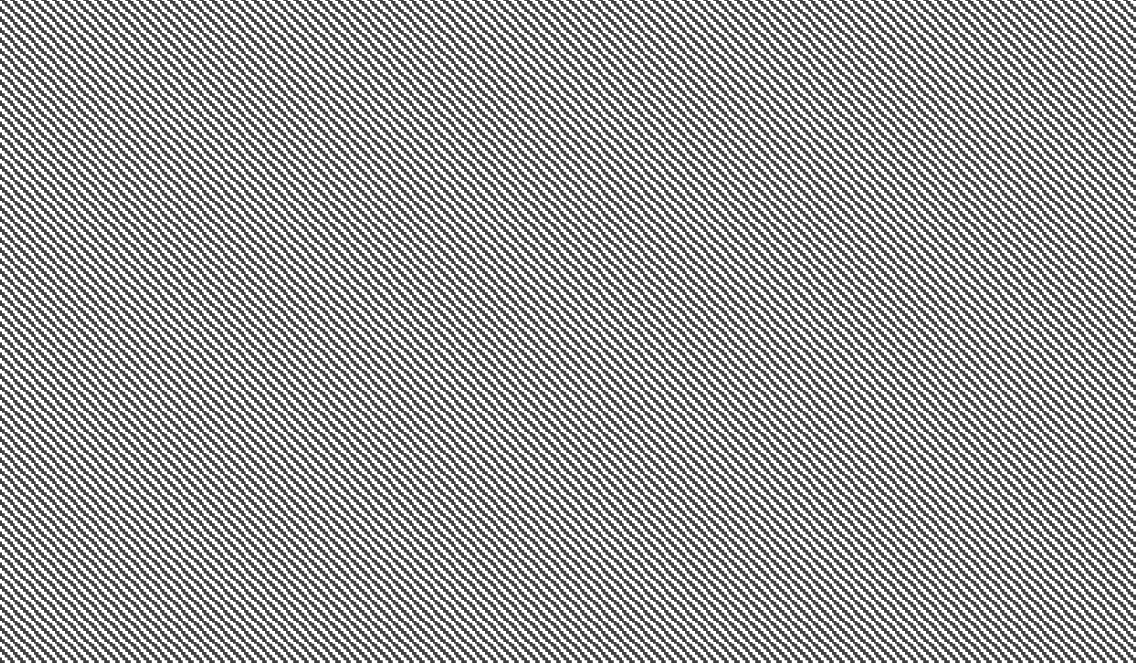

Figure 5. Responses to the survey prompt "Whether I liked it or not, the KidWind project was valuable for my learning", where $1=$ strongly disagree and $5=$ strongly agree, across three years.

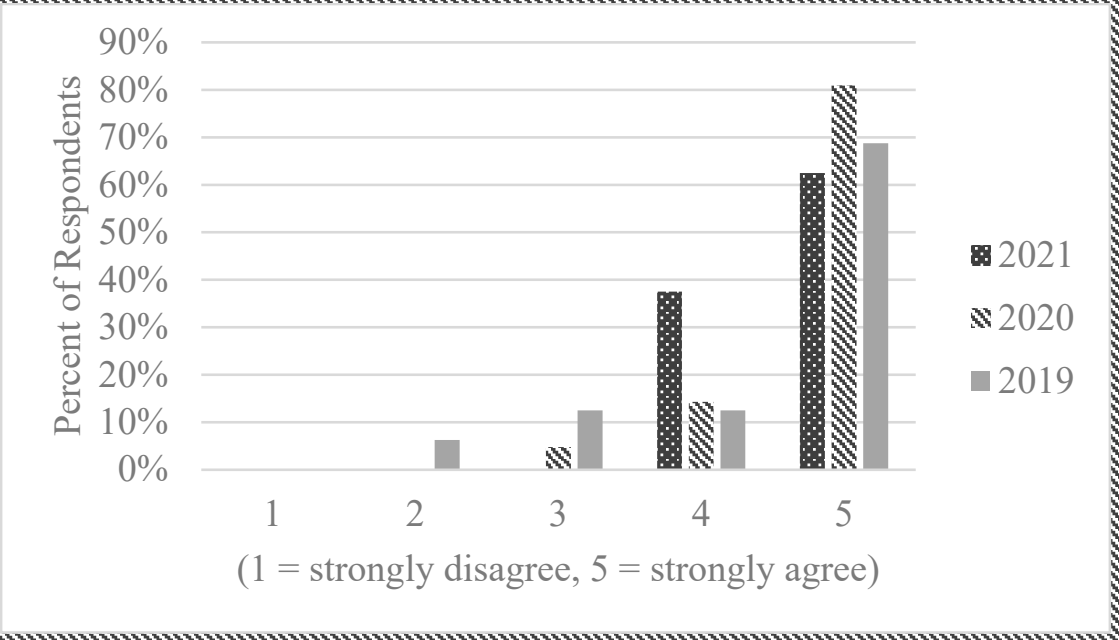

Figure 6. Responses to the prompt "I enjoyed the KidWind project", where 1 = strongly disagree and 5 = strongly agree, across three years.

The majority of students, across all years, selected that they strongly agree with the statement that the KidWind project was valuable to their learning, with most others indicating agreement. This year's project included one outlier who indicated the project was not valuable for their learning. In general, the responses were more favorable this year and last year, which is perhaps a reflection of changes that have been made since the pilot year. 
Trends in the responses to the second prompt, querying about students' enjoyment of the project, are also mostly favorable. Many students strongly agreed that they enjoyed the project. This year's feedback includes more scores of four than in previous years, which may be a reflection of the intensified challenges of the project due to teaching the fourth graders remotely.

Finally, students were asked whether they would add this project to their resumes (yes or no). Across three years of administering this survey, only one out of sixty participants responded that they would not add this project to their resume.

\subsection{Narrative Assessment}

Examination of the students' written work provides a richness to our understanding of their growth and educational gains, as well as details about the challenges they encountered. Engineering students completed a pre-project reflection, five weekly reflections during the teaching portion of the project, and a final reflection following the final celebration event. Additionally, the engineering students created final project portfolios describing the scope of their work, which also serves as an archive for their lesson plans and associated teaching materials. One section of the portfolio required students to reflect on their own learning from this community engagement project. The reflections, portfolios, and end-of-semester survey responses are analyzed here to better understand the experiences of the college students who participated in this year's project.

A common theme in many of the students' reflections was the gains they made in their communication skills, which in some cases also led to a deepened understanding of the course content. Through being challenged to explain concepts to various audiences, students grew in their ability to identify appropriate vocabulary, as indicated in the selected passages below.

[The project] helped me develop a deepened understanding of the course material because of the fact that condensing a college level engineering concept into 4th grade language is not an easy thing to do and requires that I have a good understanding of the concept myself.

I was able to explain engineering topics to not only the fourth graders, but also the fourth-grade teacher and my education major partners. It took a little time for me to adjust to using different vocabulary, but I think I could explain any of the topics we covered to any audience.

I think my technical communication skills have improved significantly since the start of the KidWind project. [ ... I I think having to explain multiple topics to the students about wind energy improved my communication skills and my understanding of the course material.

In addition to growth in communication skills, students also pointed to developing their ability to manage projects, solve problems, and remain flexible. The added reliance on technology in this year's project was a common theme. While technology added to the challenge of the project implementation, it also pushed students to think on their feet and remain calm under pressure.

One other major takeaway I found is that even daunting seeming projects can be accomplished comfortably if the project is organized well, and tasks are broken into small pieces.

I further developed my problem-solving skills as we had to face technical difficulties and other challenges from teaching over Zoom.

Technical issues from websites, internet connection, and a lack of hands-on learning limited us for each lesson and taught us to be adaptive to every lesson. During each lesson multiple backup plans were made in case if activities went wrong or if we ran out of time, which allowed us as teachers and teacher assistants to communicate with each other and plan for worst case scenarios. 
The theme of technology also arose in more overt ways, as students shared the new skills they gained in specific software packages. Further, reflections pointed to the reaped benefit of learning new technologies quickly and the ways in which that may become useful as they launch into their professional careers.

Teaching in a remote setting threw an even bigger learning curve into all of the lessons, but it was a great experience to have for our futures going forward. This remote setting will be a huge aspect in life as we know it as society tries to recover from the pandemic and adapt to the ultimate "new normal".

We also improved our skills with different forms of technology. While creating the lessons, we learned about Menti, Kahoot, Jamboard, and Flipgrid. These are all very fun and interactive ways to get the kids involved and excited about the class. We utilized all of these in our lessons, sometimes multiple in a lesson. Although these platforms are not likely to be used in the professional engineering field, adapting to new technology quickly is a good skill to have.

While many positive impacts on student learning outcomes were discussed in the reflections, there were also many challenges, in many ways tied to the impacts of the pandemic. Students pointed to the intense difficulties brought on by implementing this project remotely. Moreover, students unambiguously advocated for this project to be carried out in-person, as much as possible. One of the primary challenges of teaching remotely was facilitating the hands-on activities, in which the college students could not circulate to diagnose issues nor provide direct assistance, as evidenced by the narratives below.

The construction of the windmills was difficult considering the fact we could not physically help the students when they ran into trouble with their design. All we could do was give a slow explanation of each design step as well as a demonstration of how it should be built.

One of the biggest issues with doing a project over videochat is that you are limited to one person talking at a time. In a normal class environment, students would be able to help each other, and we could circulate around the room and help kids in need. We tried to minimize the impact of this issue by using breakout rooms so that we could have four people talking at once to a smaller group, but that does not solve all of the problems such as if the students physically can't do something. For example, one of my students did not know how to tie a knot in his string. This would have been easily fixed if I were next to him and could tie it for him, but I needed to explain how he could use tape instead.

We tried to have them show their designs on camera so I could see the issue but in many instances they only showed it for a split second, so I couldn't figure out the exact problem.

Additionally, the college students and their fourth graders shared that the materials for the windmill kits, used for the first time this year, were difficult to work with. Each kit included a small roll of washi tape, which was not sufficiently sticky. Further, the green floral foam did not work well and could have been done away with entirely.

We would change the materials the kids were given for the windmills. The green foam did not work well and caused a lot of frustration for the kids.

The students seemed very happy with KidWind this year, but they did have complaints about the materials in the kits. The tape was not sticky enough. All students agreed that the green foam did not work. They suggested white Styrofoam or doing away with the foam completely. I built my windmill without the foam and it worked much better.

Providing materials to the distance learners proved to be difficult, as the equipment needed to be left at the schools' front offices well in advance of the lesson to provide parents ample lead time to pick-up items and bring them home. In some cases, the lead time was not long enough, leaving some fourth-grade distance learners without materials during their online lessons. 
Although this paper focuses on the learning outcomes for the college students, at least anecdotally the fourth graders also gained new technical knowledge and a strengthened appreciation of wind energy. The engineering students shared many stories in their teaching reflection highlighting not only their enjoyment of the project, but also the fourth graders.

We discussed how changing the angle can help the blades spin faster up to a certain point. They really understood pitch angle and it was fun to see them experiment. I had one girl show everyone her fan and she tested it under her ceiling fan.

The students did well on the homework assignments we gave them and were able to explain how their windmills worked. The students were very excited throughout the project. The review at the beginning of each lesson showed us that the students remembered and understood the topics of the previous lesson.

We also talked about aesthetics of wind turbines because they decided they wanted to put koala stickers on their blades!

It seems like the students had a lot of fun and it was definitely exciting to hear them talking about what worked and what didn't work in their designs and why that was the case. It was also exciting to watch their reactions when the blades worked, because they were so happy and you could tell how proud they were!

\section{Conclusions}

This paper describes and measures the impacts of the implementation of three years of a cross-disciplinary community engagement project, connecting students in engineering and education courses, as a tool for teaching about wind energy, engineering design, and science education. Further, this project educates local fourth graders in a region where offshore wind energy is seeing continued expansion, while providing professional development for their teachers to grow in their ability to teach engineering. The project was motivated by the local school district's need for engineering teaching support due to the adoption of the NGSS in Rhode Island, growth in the local wind industry, and the desire to deepen college students' skills through hands-on learning.

Each year, the project begins with a professional development event for the fourthgrade teachers, delivered by university faculty. Next, engineering and education students collaborate to create, and teach, an arc of five lessons on engineering design and wind energy in an assigned fourth grade classroom-delivered remotely this year. The project culminates with celebration events to acknowledge the hard work of all the students.

Despite the continuity of the project over three years, each implementation has been markedly different due to the impacts of COVID-19. The pilot year was administered entirely in person. The second year began with an in-person professional development event, followed by two classroom lessons taught to each fourth-grade class. The arrival of COVID-19 in the United States required an abrupt change to the remaining three lessons, which were created but not taught. In year three, the project was completed entirely remotely, including five online lessons taught in each of the thirteen fourth-grade classrooms. This work is unique not only for the project's design, but moreover for the measurement of program success, across three distinct modes of implementation, due to the COVID-19 pandemic. The data collected across three years of project-implementation provide insights in the effects of community engagement modalities on students learning.

To answer the first research question pertaining to the impacts of the project on student learning and growth, students' responses to the modified TESS were analyzed. Engineering and education students' responses to pre- and post-tests, adapted from TESS [35], demonstrated growth across all survey prompts in both the 2019 and 2021 projects (the post-test was not administered in 2020). Additionally, engineering students completed an end-ofproject survey each year, which consistently identified teamwork, communication, thinking on your feet, and project planning as major growth areas. Narratives from engineering students' reflection assignments provide a richness to understanding their development, as well as the challenges they confronted. 
To address the second research question, which seeks to understand the differential impacts of each year's unique project implementation, assessment data are compared across time. In 2019 and 2021, changes in the median TESS scores from pre- and post-tests were all positive or unchanged. Delving deeper, in 2021, the responses to the end-of-semester engineering survey about skill development were slightly lower than in previous years. In addition, this year's responses to the survey prompt "I enjoyed the KidWind project," include less scores of five (strongly agree) than in previous years. These survey findings may suggest student learning was not as strong in 2021, as compared to previous years, due to COVID-necessitated project changes.

Finally, investigation of student narratives provides insights to answer the third research question-how can this or other similar projects be improved for the future? Engineering students shared that this year's project was challenging due to the reliance on technology, as well as inability to interact with the fourth-graders in-person, especially when guiding them through the hands-on building process for the windmills and wind turbines. Many students acknowledged the unavoidable challenges presented by the ongoing pandemic in their discussion of this year's elevated difficulties. However, one student's comment drove straight to the heart of the matter, by saying "I would put a hold on the project until it can be done in person again".

While video conferencing software allowed the project to occur during a year when in-person activities were not possible, it is not a model that should be sustained. When college students are teaching in-person, the community engagement project is limited to a relatively small geographical area, as students must be able to drive to the elementary schools during their own busy class days. Online teaching allows for the expansion of the project's geographical area, but challenges the hands-on, experiential nature of the project for both the college and elementary school learners. The benefits of face-to-face interactions in this type of cross-disciplinary community engagement projects cannot be replicated through computer screens. It is therefore recommended that, if safety protocols allow, this work be returned to an entirely in-person modality.

The framework for this interdisciplinary community engagement project that teaches local elementary school children and their teachers about engineering design and wind energy could be generalized for other topics in renewable energy, sustainability, engineering, or even more broadly to the humanities. The use of wind turbine kits was selected based on regional relevance, but could be replaced with other kits, such as solar energy devices or underwater sea vehicles. The three-tiered design of the project has worked well for the authors, in which the program begins each year by training local teachers, then requires college students to create and implement lessons for elementary-aged students, and then culminates in a celebratory event. Though this project was implemented as part of two academic courses, the model could be adapted for use by student clubs or companies that are seeking to engage with their local community.

This project will continue to be implemented for at least another two years. Pre- and post-project assessment data will continue to be collected and analyzed across the four participant populations - fourth graders, fourth-grade teachers, education students, and engineering majors - and will shed further light on the impacts of project implementation going forward. For example, the return to fully in-person classroom instruction cannot be guaranteed, as the COVID-19 pandemic continues to evolve. Regardless of the modality, the project will continue to allow our university to engage with the local community in a way that helps aid the transition to a more sustainable future.

Author Contributions: Conceptualization, M.A.B. and L.-L.Y.; methodology, M.A.B. and L.-L.Y.; analysis, M.A.B. and L.-L.Y.; writing-original draft preparation, M.A.B.; writing-review and editing, M.A.B. and L.-L.Y.; visualization, M.A.B.; project administration, M.A.B. and L.-L.Y.; funding acquisition, M.A.B. and L.-L.Y. Both authors have read and agreed to the published version of the manuscript. 
Funding: This research was funded by The Rhode Island Foundation, grant number \#6009_20210386, with additional support from the Hassenfeld Community Projects fund, the RWU Foundation to Promote Scholarship and Teaching, and TPI Composites in Warren, RI.

Institutional Review Board Statement: The study was conducted according to the guidelines of the Declaration of Helsinki and approved by the Institutional Review Board of Roger Williams University (protocol code \#20210201MB and date of approval 2 February 2021).

Informed Consent Statement: Informed consent was obtained from all subjects involved in the study.

Data Availability Statement: Not applicable.

Acknowledgments: Many thanks to our undergraduate research assistants, Raquel Santos and Riley Keenan, for their support in collecting, entering, and analyzing project assessment data, as well as providing logistical support and guidance for this year's student-teachers. We are grateful for the continued partnership with the Bristol-Warren Regional School District, whose teachers, principals, and administrators provide support to both their students and ours.

Conflicts of Interest: The authors declare no conflict of interest.

\section{References}

1. Benitz, M.A.; Yang, L. Adapting a community engagement project in engineering and education to remote learning in the era of COVID-19. Adv. Eng. Educ. 2020, 8, 1-8.

2. Vernier. Available online: https://www.vernier.com/product/kidwind-basic-wind-experiment-kit/ (accessed on 18 May 2021).

3. Transforming Our World: The 2020 Agenda for Sustainable Development; United Nations General Assembly: New York, NY, USA, 2015.

4. The SDGs in Action, United Nations Development Programme. 2021. Available online: https://www.undp.org/sustainabledevelopment-goals (accessed on 4 August 2021).

5. Fonseca, L.M.; Domingues, J.P.; Dima, A.M. Mapping the Sustainable Development Goals Relationships. Sustainability 2020, 12, 3359. [CrossRef]

6. Sher, F.; Curnick, O.; Azizan, M. Sustainable Conversion of Renewable Energy Sources. Sustainability 2021, 13, 2940. [CrossRef]

7. Stephens, J.; Graham, A.C. Toward an empirical research agenda for sustainability in higher education: Exploring the transition management framework. J. Clean. Prod. 2010, 18, 611-618. [CrossRef]

8. Hoople, G.D.; Chen, D.A.; Lord, S.M.; Gelles, L.A.; Bilow, F.; Mejia, J.A. An Integrated Approach to Energy Education in Engineering. Sustainability 2020, 12, 9145. [CrossRef]

9. Swift, A.; Tegen, S.; Acker, T.; Manwell, J.; Pattison, C.; McGowan, J. Graduate and undergraduate university programs in wind energy in the United States. Wind. Eng. 2018, 43, 35-46. [CrossRef]

10. Artigao, E.; Vigueras-Rodríguez, A.; Honrubia-Escribano, A.; Martín-Martínez, S.; Gómez-Lázaro, E. Wind Resource and Wind Power Generation Assessment for Education in Engineering. Sustainability 2021, 13, 2444. [CrossRef]

11. Schlossberg, T.; America's First Offshore Wind Farm Spins to Life. The New York Times. Available online: https://www.nytimes. com/2016/12/14/science/wind-power-block-island.html (accessed on 14 June 2021).

12. Schneider, G.S. Virginia's First Offshore Wind Turbines Promise Jobs and Clean Power. They Won't Come Cheap. Washington Post. Available online: https://www.washingtonpost.com/local/virginia-politics/virginia-offshore-wind-turbines/2020/06/ 30/5e4eb518-bacf-11ea-bdaf-a129f921026f_story.html (accessed on 14 June 2021).

13. Brady, J. Biden Administration Pushes Major Expansion for Offshore Wind Energy. National Public Radio. Available online: https: / / www.npr.org/2021/03/29/982285907/biden-administration-pushes-major-expansion-for-offshore-wind-energy (accessed on 14 June 2021).

14. Hoen, B.; Firestone, J.; Rand, J.; Elliot, D.; Hübner, G.; Pohl, J.; Wiser, R.; Lantz, E.; Haac, T.R.; Kaliski, K. Attitudes of U.S. Wind Turbine Neighbors: Analysis of a Nationwide Survey. Energy Policy 2019, 134, 110981. [CrossRef]

15. Next Generation Science Standards (NGSS). Achieve, Inc. on Behalf of the Twenty-Six States and Partners That Collaborated on the NGSS. 2013. Available online: https:/ / www.achieve.org/next-generation-science-standards (accessed on 18 August 2021).

16. Committee on a Conceptual Framework for New K-12 Science Education Standards; Board on Science Education; Division of Behavioral and Social Sciences and Education; National Research Council. A Framework for K-12 Science Education: Practices, Crosscutting Concepts, and Core Ideas; The National Academies Press: Washington, DC, USA, 2012.

17. RI State Science Standards, Rhode Island Department of Elementary and Secondary Education. Available online: http:/ /www. ride.ri.gov/InstructionAssessment/Science/ScienceStandards.aspx (accessed on 14 June 2021).

18. Jacoby, B. Service Learning in Higher Education; Jossey Bass: San Francisco, CA, USA, 1997.

19. Bringle, R.G.; Hatcher, J.A. A Service-learning Curriculum for Faculty. Mich. J. Community Serv. Learn. 1995, 2, 112-122.

20. Hatcher, J.A.; Bringle, R.G. Reflection: Bridging the Gap between Service and Learning. Coll. Teach. 1997, 45, 153-158. [CrossRef]

21. Johnson, E.; Rodich, E.; French, H.; Thomas, A. Designing Little Free Libraries for Community Partners in a First-Year Graphics and Design Course. In Proceedings of the ASEE Annual Conference and Exposition, Montreal, QC, Canada, 23 June 2020. 
22. Koh, R. Engagement in Practice: Community Engaged Capstone Design Experience. In Proceedings of the ASEE Annual Conference and Exposition, Montreal, QC, Canada, 23 June 2020.

23. Bielefeldt, A.R.; Dewoolkar, M.M.; Caves, K.M.; Berdanier, B.W.; Paterson, K.G. Diverse Models for Incorporating Service Projects into Engineering Capstone Courses. Int. J. Eng. Educ. 2011, 27, 1206.

24. Pe, K.P.; Sheumaker, D.L.; Allen, C.R. Engineers Without Borders-Montana State University: A Case Study in Student-Directed Engagement in Community Service. In Proceedings of the ASEE Annual Conference and Exposition, New Orleans, LA, USA, 26-29 June 2016.

25. Lawson, W.D.; Keister, H.R. Professional Ethics LIVE!-A Community Partnership. In Proceedings of the ASEE Annual Conference and Exposition, Montreal, QC, Canada, 23 June 2020.

26. Gaskins, W.; Pritchard, T.; White, D.; Eason, K.K. Parents' Perceptions of STEM Education in Black Churches. In Proceedings of the ASEE Annual Conference and Exposition, Montreal, QC, Canada, 23 June 2020.

27. Bernard, B.R.; Straub, J.; Marella, P.K. Work in Progress: The Role of Student Counselors at Cybersecurity Summer Camps. In Proceedings of the ASEE Annual Conference and Exposition, Montreal, QC, Canada, 23 June 2020.

28. Yan, Y.; LaFratta, M.A.; Perry, L.G.; Jack, H. Engagement in Practice (EIP): Differences in Perceptions between Engineering and Art Students in an Interdisciplinary Service-Learning Project. In Proceedings of the ASEE Annual Conference and Exposition, Montreal, QC, Canada, 23 June 2020.

29. MacNamara, S.; Bowne, L.; Ii, L.D.B. Controlled Chaos: Modeling Interdisciplinary Practice for Architecture and Engineering Students in a Real World Community Engaged Design Project. In Proceedings of the ASEE Annual Conference and Exposition, Seattle, WA, USA, 14 June 2015.

30. Lu, W.; Natarajarathinam, M.; Campbell, M.E.; McDougal, M.K.; Holder, L.N. Engagement in Practice: Engaging Undergraduate Students in a Multidisciplinary Service-Learning Environment. In Proceedings of the ASEE Annual Conference and Exposition, Salt Lake City, UT, USA, 24 June 2018.

31. Manwell, J.F.; McGowan, J.G.; Rogers, A.L. Wind Energy Explained: Theory, Design and Application; Wiley: Chichester, UK, 2009.

32. KidWind. Available online: https:/ / www.kidwind.org/activities/recharge-labs (accessed on 18 May 2021).

33. Kahoot! Available online: https:/ / kahoot.com/ (accessed on 18 May 2021).

34. Jamboard, Google. Available online: https://jamboard.google.com/ (accessed on 18 May 2021).

35. Yoon, S.Y.; Evans, M.G.; Strobel, J. Development of the Teaching Engineering Self-Efficacy Scale (TESS) for K-12 Teachers. In Proceedings of the ASEE Annual Conference and Exposition, San Antonio, TX, USA, 10 June 2012.

36. Bandura, A. Self-efficacy: Toward a Unifying Theory of Behavioral Change. Psychol. Rev. 1977, 84, 191-215. [CrossRef] [PubMed]

37. Sullivan, G.M.; Artino, A. Analyzing and Interpreting Data from Likert-Type Scales. J. Grad. Med. Educ. 2013, 5, 541-542. [CrossRef]

38. Gere, A.R. Teachers as researchers. Natl. Writ. Proj. Netw. Newsl. 1984, 7, 1-2.

39. Nickoson, L. Revisiting teacher research. In Writing Studies Research in Practice: Methods and Methodologies; Nickoson, L., Sheridan, M.P., Eds.; Southern Illinois University Press: Carbondale, IL, USA, 2012.

40. Stock, P.L. 2004 NCTE Presidential Address: Practicing the Scholarship of Teaching: What We Do with the Knowledge We Make. Coll. Engl. 2005, 68, 107. [CrossRef]

41. Rosenman, R.; Tennekoon, V.; Hill, L.G. Measuring Bias in Self-Reported Data. Int. J. Behav. Healthc. Res. 2011, 2, 320-332. [CrossRef] [PubMed] 